\title{
MUDANÇAS ONTOGENÉTICAS NA MICROANATOMIA DA CAVIDADE ORAL EM GIRINOS DE BOKERMANNOHYLA OXENTE (HYLIDAE) E DERMATONOTUS MULLERI (MICROHYLIDAE)
}

\author{
$\underline{\text { Sidiane da Silva Oliveira }}^{1}$; Flora Acuña Juncá ${ }^{2}$
}

1- Bolsista FAPESB, Graduanda em Licenciatura no curso de Ciências Biológicas, Universidade Estadual de Feira de Santana, e-mail:

$\underline{\text { Sidianesoliveira@gmail.com }}$

2-Flora Acuña Juncá, Departamento de Ciências Biológicas, Universidade Estadual de Feira de Santana, e-mail:

\section{Florajunc@gmail.com}

PALAVRAS CHAVE: morfologia, cavidade oral, desenvolvimento ontogenético,

\section{INTRODUÇÃO}

Girinos apresentam uma alta diversidade morfológica especialmente se consideramos este estágio na construção da história de vida destes organismos. (MCDIARMID \& ALTIG, 1999). Além da grande diversidade morfológica, estes apresentam muitas estruturas especializadas, dentre estas estão as do aparato oral. (DUELLMAN \& TRUEB, 1994; WELLS, 2007). O disco oral e a cavidade oral são regiões distintas tanto em estrutura quanto a função sendo altamente especializadas e associadas à dieta. $\mathrm{O}$ disco oral é composto basicamente de um bico córneo, pelo qual o girino raspa o substrato ou tira pedaços do alimento, fileiras de dentes, que auxiliam na tomada de alimento e as papilas sensoriais. Já a cavidade oral apresenta regiões especificas, como por exemplo, arena pré- e pós-nasal, uma série de papilas de formas, tamanhos e alinhamentos diferentes (ALTIG \& MCDIAMIRD, 1999). Estudos atuais têm indicado que as características morfológicas da cavidade oral são menos influenciadas pelos fatores externos, podendo complementar a diagnose mais segura da espécie pois são relativamente fáceis de analisar e apresentam alto valor adaptativo, diretamente ligado à alimentação (WASSERSUG, 1976). Após eclodir (estádio 25) na forma de larva livre natante, a maioria dos girinos com desenvolvimento exotrófico passam por uma série de mudanças ontogenéticas até concluírem seu desenvolvimento, que ocorre após a metamorfose (ALTIG \& MICDIARMIND, 1999). Ao longo destas mudanças diversas modificações morfológicas ocorrem de modo a reorientar as mais diversas estruturas a fim de atender as demandas do organismo adulto. Dentre estas, pode-se citar as do aparato oral, que estão em sua essência ligadas a tomada de alimentos. No entanto poucos trabalhos foram realizados para descrever as estruturas da morfologia oral. Neste escopo, este trabalho teve por objetivo estudar a variação e modificação de estruturas da cavidade oral em girinos de Bokermannohyla oxente e Dermatonotus mulleri ao longo do seu desenvolvimento ontogenético com a finalidade de auxiliar no entendimento da posição na cadeia trófica dos girinos ao longo do seu desenvolvimento, bem como indicar padrão de desenvolvimento nas estruturas da cavidade oral.

\section{MATERIAIS E MÉTODOS}

Para o estudo da cavidade oral de ambas as espécies (D. mulleri e B. oxente) realizou-se primeiramente a identificação do estádio de desenvolvimento larvar com base em Gosner (1960). Foram escolhidos de acordo com a disponibilidade quantitativa cinco girinos de 
cada estádio para a análise da morfologia oral. Para a espécie $B$. oxente foram analisadas os estádios 25, 27, 29, 36 e 41. Para D. mulleri, foram analisadas as fases 25, 27, 29 e 31. Os girinos foram lavados para retirar o excesso de formol. Com o auxílio de um estereomicroscópio e tesoura cirúrgica foi feito um corte começando no canto esquerdo da boca entre os bicos superiores e inferiores, até atingir a faringe e transversalmente à boca, além de um corte longitudinal ao longo da boca para libertar o assoalho bucal do teto. A seguir, as estruturas orais foram pigmentadas com corante azul De metileno para melhor visualização e identificação das estruturas. Para a caracterização da morfologia oral, foi utilizada a nomenclatura baseada em Wassersug (1976). As estruturas identificadas foram fotografadas com o auxílio de Lupa Leica (modelo LASEZ) e os resultados comparados com outros existentes na literatura. Os exemplares estudados encontram-se disponíveis na coleção de anfíbios anuros no MZUEFS.

\section{RESULTADOS E DISCUSSÃO}

A morfologia oral de B. oxente é caracterizada por possuir dois pares de papilas infralabiais (PI) com formatos distintos, e um par de papilas linguais (LP) bem discerníveis, além de numerosas papilas laterais à arena do assoalho. Os bolsos bucais (BP) são bem desenvolvidos sem perfurações e precedidos de cinco papilas coniformes com tamanhos variados. A maior quantidade de papilas cerca de trinta, de formato coniforme e tamanho variados, encontra-se posterior aos bolsos bucais, próximo ao velum ventral. A arena do assoalho apresenta apenas pustulações (Figura 1). O velum ventral (VV) é bem visível e dividido na região mediana, tem bordas onduladas e apresenta de 68 projeções coniformes; zona glandular restrita a uma faixa estreita ao bordo velar, sendo bastante desenvolvida; glote localizada no meio do VV estreita, pequena e disposta de forma a se encaixar com a divisão mediana do velum. O teto bucal é largo e translucido (Figura 2). Arena pré-nasal apresenta quatro papilas. A primeira tem formato semicircular. $\mathrm{Na}$ arena pós-nasal há dois pares de papilas pontiagudas e compridas. $\mathrm{O}$ segundo par é maior que o primeiro e estão localizados à frente da crista mediana. A crista mediana (CM) tem formato foliar serrilhado, seu ápice é mais estreito que a base e está voltado para a abertura da boca. A arena do teto é isenta de papilas, e apresenta inúmeras pustulações. O velum dorsal é largo nas extremidades opostas. A zona glandular é bastante desenvolvida e está localizada em uma faixa superior ao bordo velar. Nos estádios 25, 27, 29 e 31, o assoalho bucal e o teto bucal apresentam formato triangular. Nota-se que de modo geral ocorreram poucas mudanças na morfologia oral de $B$. oxente com as mais marcantes ocorrendo nos estágios que se aproximam da metamorfose (36 e 41). Estas mudanças incluem alterações no número de papilas, disposição e forma destas estruturas; além disso, nos estágios finais há um alargamento tanto do assoalho bucal quanto do teto. A mudança mais marcante ocorreu na PL, que dará lugar a língua. Notase que esta papila aumenta de tamanho e forma, passando de semicircular para triangular globosa, ao passo que suas projeções fundem e encurtam-se. Estas mudanças coincidem com a proximidade da metamorfose, pois a medida que o girino cresce diversas estruturas de seu aparto oral são perdidas ou reestruturadas de modo que possam suprir o hábito alimentar do adulto, que é carnívoro. Estes resultados estão de acordo com outras espécies pertencentes ao gênero Bokermannoyla que tiveram a morfologia da cavidade oral descrita (HEURSEL \& HADDAD, 2007). Para D. mulleri as mudanças ocorridas ao longo dos estágios são menos marcantes e estão associadas principalmente a tamanho e formato das papilas do assoalho bucal. A morfologia desta espécie é caracterizada principalmente pela ausência de estruturas queratinizadas e de papilas linguais. As 
variações mais evidentes ocorreram na região pré-nasal, (teto bucal) na qual há uma tendência de complexidade no formato da papila, que passa de uma protuberância simples para quadrangular com algumas projeções digitiformes. A região infralabial sofreu poucas variações. $\mathrm{O}$ assoalho é em forma de U. Nas laterais dos lábios, há em cada lado uma papila curta de formato digitiforme. Anterior aos BP encontra-se três papilas curtas e digitiformes. Na fase 25 estas papilas apresentavam o mesmo formato, no entanto observa-se que nos estádios 29 e subsequentes, estas papilas passam a apresentar margens serrilhada e maior tamanho. O VV possui bordas onduladas. O teto bucal apresenta mesmo formato do assoalho. Na arena pré-nasal há um conjunto de papilas digitiformes dispostas de modo a formar um semicírculo. Na região pós-nasal e lateralmente a CM há em cada lado, três papilas de formato coniforme foliar, as externas são maiores e as internas são coniformes, curtas e sem ramificações. A CM é larga em sua base e se estreita nas pontas. De modo geral, a morfologia da cavidade oral das espécies investigadas sofreu poucas variações ao longo do desenvolvimento ontogenético e as mudanças mais acentuadas surgem nos estádios mais próximos da metamorfose, como observado em $B$. oxente. Para $D$. mulleri, não foi possível afirmar essa tendência, uma vez que as estruturas orais desta espécie surgem nos estádios mais avançados. Quando comparada a morfologia de ambas as espécies nota-se que as estruturas orais são bastante distintas, essas mudanças podem servir como caráter taxonômico para a identificação de espécies, principalmente através de chaves de identificação. No entanto é relevante considerar que nem sempre estas estruturas são conservadas, portanto a anatomia da cavidade oral serve como um suporte que juntamente com outros caracteres podem ser usados na diagnose mais segura das espécies de anuros.

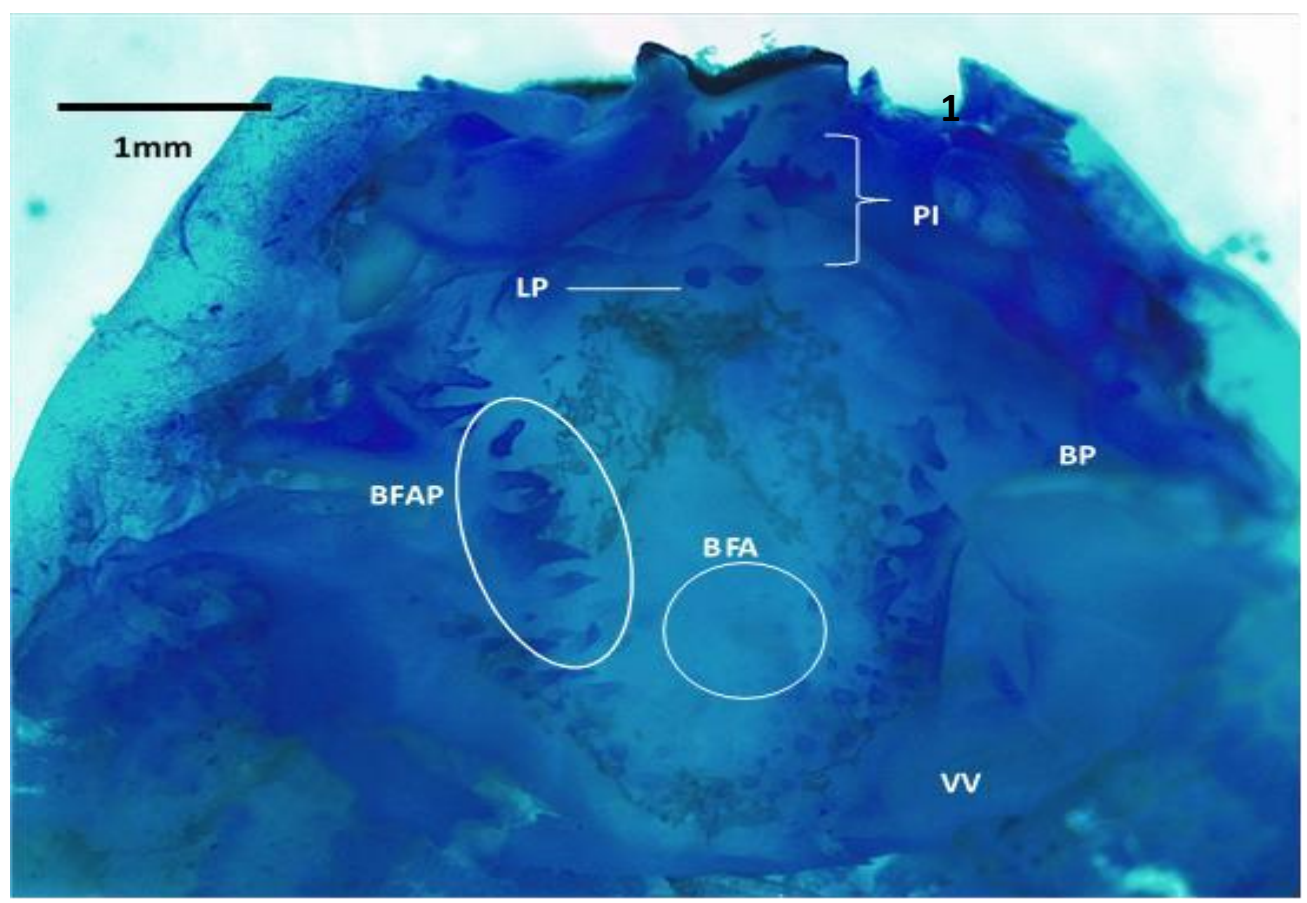

Figura 1. Assoalho bucal de B. oxente estádio 25. PI: papilas infralabiais; LP: papila lingual; BP: bolso bucal; BFA, arena do assoalho bucal; BFAP; papilas da arena do assoalho; VV: velum ventral. 


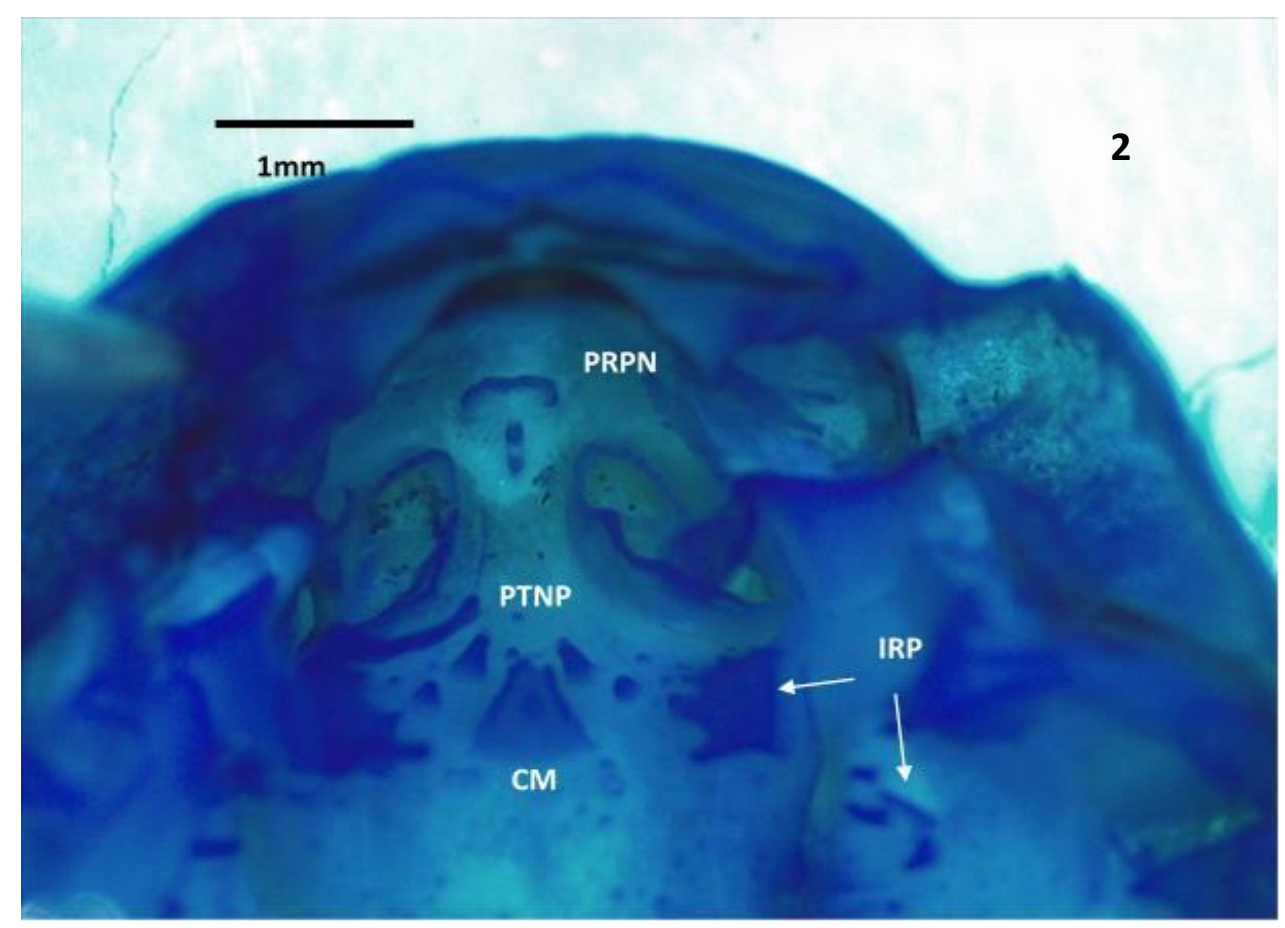

Figura 2. Teto bucal de B. oxente estádio 25. PRPN: Arena pré-nasal; PTNP: papilas pósnasais; CM: Crista mediana; LRP; papilas laterais à crista mediana.

\section{REFERÊNCIAS BIBLIOGRÁFICAS}

ALTIG, R. \& R. W. MCDIARMID 1999. Body plan: Development and Morphology. In: R. W McDiarmid \& R. Altig, Tadpoles. The biology of anuran larvae, 24-51 pp. The University of Chicago, Chicago.

D'HEURSEl, A. and HADDAD, F. B. C. 2007. Anatomy of the Oral Cavity of Hylid Larvae from the Genera Aplastodiscus, Bokermannohyla, and Hypsiboas (Amphibia, Anura): Description and Systematic Implications. Journal of Herpetology, 41(3):458468p.

DUELLMAN, W. E. \& TRUEB, L. 1994. Biology of Amphibians. Mc Graw- publisihing Company, 3. Ed. São Paulo, 670 p.

ECHEVERRÍA, D. D. and LAVILLA, E. O. 2000. Internal Oral Morphology of Tadpoles of Dermatonotus muelleri and Elachistocleis bicolor. Journal of Herpetology. 34: 517$523 \mathrm{p}$.

GOSNER, K. L. 1960. A simplified table for Staging Anuran Embryos and Larvae with Notes on Identification. Herpetologica 16(3): 183-190p.

WASSERSUG, R. J. 1976. Oral morphology of anuran larvae: terminology and general description. Occassional Papers. Museum of Natural History University of Kansas 48: 1$23 \mathrm{p}$.

WELLS, K. D. 2007. The Ecology and Behavior of Amphibians. The University of Chicago Press, London 1148 p. 